\title{
Mutual Shaping of a CMS for Social Journalism in a Hierarchical News Organization
}

Mark A. Poepsel

This article presents a case study of a news organization examined when it was introducing a proprietary content management system (CMS) for social journalism in the form of a health news website. The CMS enabled users to publish, form groups, and follow one another to create personalized local health news feeds. Applying the mutual shaping of technology (MST) construct in analysis, organized according to the hierarchy of influences model, this article examines how the CMS influenced the news organization and vice versa. Even in an organization with a great deal of control over a small innovation, the predominant perception was that the CMS was a technological incursion rather than a tool to be molded. Instead of asserting professional norms over the technology as social shapers, journalists focused on managing changes in routines and organizational structures and on managing perceptions about the "experiment." The project has stagnated. This article discusses why, and it addresses the usefulness of the MST construct for examining innovation iterations in news organizations.

\section{Keywords}

Social journalism, content management systems, mutual shaping, diffusion of innovations, hierarchy of influences, newsroom studies

\section{INTRODUCTION}

Mass communication scholars interested in evolving information and communication technologies and their impact on the field of journalism have argued convincingly that the news media of the future will be liquid, in a constant state of flux (Deuze, 2006, 2008, 2011; Karlsson \& Strömbäck, 2010; Singer, 2011). Journalism will likely be "ambient" - ubiquitously accessible via networked technologies (Hermida, 2010, 2012). News media of the future, they argue, will be more and more participatory in struc- ture and conversational in tone (Bardoel, 1996; Bardoel \& Deuze, 2001; Boczkowski, 2004b; Karlsson \& Strömbäck, 2010; Lewis, 2012; Nip, 2009; Singer et al., 2011). These are reasonable assertions. What is lacking in this line of inquiry is research examining how a news organization might function when it has the means to develop its own socially networked news platform. What can happen when a news website attempts to ride the wave of technological change and create its own form of ambient journalism? In this case study, an organization developing a socially networked news content management system (CMS) was examined in depth to see how the development of the CMS influenced journalists and how they in turn shaped its features and functions.

This study, originally conducted for Poepsel's 2011 dissertation, describes the organization during a brief period when the social journalism CMS was developed and introduced. The CMS was deployed in 
the form of a health news network, a website where users and journalists had access to the CMS to publish blurbs, blogs, and even marketing materials. To the user, it looked like blogging software with the added ability to join groups and to follow users or groups to create a personalized health news feed. To the journalists, the same posting and networking features were made available, but they had additional editorial controls. Journalists could delete user posts, although they generally tried to avoid it.

The organization in question started in 1911 as a newspaper company and at the time of this study, published its flagship print newspaper, a free-to-access online version, and several regional print publications. Just prior to the first interview for this study, the organization sold its cable television operation, which included a local television station and internet service provider capabilities. Many journalists in the news organization had experience producing for print, web, and television. Additionally, the organization had successfully marketed a CMS for small "online newspapers" complete with an advertising platform.

It was thought that this new CMS might be the future of the organization's newsgathering and dissemination operations as well as something it could market nationally. It was innovative as a tool for networked, social journalism. "Social journalism" is defined here as the intersection of social media capabili- ties and professional journalism activities. It follows Singer et al.'s definition of participatory journalism: "This is the term ... to describe user contributions to the newspaper website. The participation can occur at various stages of the news-production process, and it can make use of a variety of tools" (2011, p. 206). Since the tools of the CMS included social media functions, this form of participatory journalism should be called social journalism.

This article addresses the mutual shaping of the CMS. Specifically, it asks whether professionals in the organization saw its introduction primarily as an opportunity to shape the CMS or primarily as a diffusion, a change agent, perhaps a threat to their norms and routines. This is treated as a dynamic of influences, not a binary of adopt-or-not. On one side is the social shaping force, the power of users to shape technologies. It made sense to look for this type of influence because journalists and members of the public were invited early on to offer input about how the CMS should function. On the opposing side was the diffusion force. Well-documented diffusions research examines how technologies are adopted and how they spread through cultures (Rogers, 2003); however, diffusions research tends toward technological determinism (Bijker et al., 1989). Including an analysis of social shaping forces countervails that tendency.

Since this study was designed to look for both influences, evidence of both was found. The question is:
"Which seemed to prevail?" In order to break down the news company into logical parts and look at the dynamic in an organized way, the hierarchy of influences model was used (Shoemaker \& Reese, 1996, 2013; Shoemaker \& Vos, 2009). This enabled me to examine the dynamic at the individual, news routines, organizational, institutional, and social system levels of the company. The hierarchy of influences model is usually used to look at how news content is shaped and then disseminated; but, turned inward, it can be used to organize analyses of news organizations in a way that is thorough and keeping in line with myriad studies on how journalists and news organizations work (Hackett, 2006; Reese, 2001; Shoemaker \& Reese, 1996, 2013; Shoemaker \& Vos, 2009; Voakes, 1997).

Primarily, the social journalism CMS was seen as a diffusion, a change to be weathered rather than an opportunity to be grasped, but at the institutional level, where the news organization collaborated with outside groups to build the CMS, there was more evidence of social shaping. The Findings section delves into a detailed analysis at all five levels. First comes a review of relevant literature and a discussion of the qualitative method employed. After the Findings comes a brief Discussion section connecting broader theory. 
THEORETICAL FRAMEWORK

Mutual shaping of technology

This article is unique in that it applies the mutual shaping of technology (MST) construct to the development of a social journalism CMS. MST has been applied successfully to analyze emerging communication technologies. Boczkowski (1999) studied how an internet-based mailing list was developed in Argentina, and Boczkowski (2004a) also analyzed the failed use of "videotex" technology by U.S. publisher Knight-Ridder in the 1980 s in a post-mortem. Knight-Ridder's early attempt to deliver newspaper content via television and modem, in a proprietary service called Viewtron, failed:

Print's stand-alone technical infrastructure and unidirectional flow of information were reproduced in Viewtron. ... Hence, user-authored content was not fostered and its potential was mostly overlooked. As a result, Viewtron neglected its own usage data showing that adopters were more interested in communicating with each other than reading newsroom-generated content. ... The shaping of videotex newspapers cannot be understood disconnected from how their diffusion was intended to unfold ... and their diffusion cannot be understood in isolation from the ongoing process of technical construction. (Boczkowski 2004a, p. 263)
Boczkowski argues here that the diffusion of innovations theory cannot be discarded in cases like these because it matters how creators perceive and present their inventions when they hope users will adopt them. And yet, this type of failure to launch an innovation cannot simply be chalked up to the category of "failed diffusion" when there was apparently missed potential for social shaping to contribute to a version of the technology people really wanted. Using the MST framework allows researchers to get a comprehensive picture. Also, this quote from Boczkowski (2004a) in particular is highlighted because it discusses a previous failed attempt by a news organization to develop a networked news and information hub. When this happens and a researcher wants to know how, it makes sense to look at the complete innovation dynamic.

Research on innovations in journalism

There has been research on CMS adoption (Rodgers, 2015) and on user-generated content inclusion (Hermida \& Thurman, 2008), but the type of case studied here, where managers, journalists, and community members were brought into an iterative development process, is exceedingly rare. There is a need in the media innovations literature for this study because it was an effort to develop a prototype for a national product. Also, most works in this area of media in- novations research focus on adoption or rejection as a binary (Küng, 2008; Paterson \& Domingo, 2008; Singer et al., 2011). This study contributes an indepth discussion of an iterative design dynamic where some key developments along the way of adoptionor-rejection are unpacked and analyzed in hopes of explaining why such dynamics might succeed or fail.

CMS as technological innovation

It would not make sense to study the diffusion of an innovation if the product itself were not particularly innovative. The CMS in question had social media and user publishing capabilities built in. The health news and social networking site built atop the CMS allowed users to follow one another, to create groups, and to create news feeds. By following users and groups, one could tailor his or her news feed in a way that approximated following users and lists on Twitter. When a user wanted to publish, he or she had access to virtually the same interface that the professional journalists saw. Publishing controls were similar to WordPress, circa 2010. Users were encouraged to contribute multimedia news as well as marketing and advertising information. All were considered valuable in this environment, although journalists could identify and remove spam. Frequent posters of commercial information were invited to create paid-for sponsored groups. The site was, and is, underwritten 
by a local hospital. Many of the networking features have been removed or downplayed as of September 2017, although the site still functions as a health news blog to which journalists, members of the public, and marketing professionals can publish.

MST in two parts

The two competing frameworks combined in the MST dynamic are the diffusion of innovations theoretical approach, which is referred to as DI throughout this study (Rogers, 2003) and the social shaping of technology, referred to as SST (Lievrouw \& Livingstone, 2002). When Rogers published the first edition of Diffusion of Innovations in 1962, there were already hundreds of published studies using a diffusions framework in a variety of disciplines from agriculture to communication (Rogers, 2003, p. xv). The theory considers products as fully formed and seeks to explain rates of adoption (Mierzejewska, 2011). A primary concern expressed by critics of DI, however, is "that diffusion theory is technologically deterministic because it treats innovations as given and focuses more on the effects or impact of innovations in social systems" (Lievrouw \& Livingstone, 2002, p. 187).

As Flichy (2007) puts it, "the linear science-technology-use schema no longer works" (p. vi). Instead of developers coming up with innovations that people adopt or not, it is more common, particularly in software, to see some features highlighted and others dropped based on user preferences as iterations are developed (Jalote \& Agrawal, 2005). The social shaping of technology framework adds a necessary means for discussing how user input influences dynamic development in software and related ICTs (Boczkowski, 2004a; MacKenzie \& Wajcman, 1999). Thus, it makes sense to apply MST to this study of the development of a social journalism CMS.

\section{FRAMEWORK FOR ORGANIZATIONAL}

\section{ANALYSIS}

The hierarchy of influences model

The hierarchy of influences model was used to guide the data-gathering, analysis and reporting processes in this study. Rather than attempting to describe one massive dynamic of diffusive and social forces, five smaller dynamics were identified that were easier to manage and discuss. Shoemaker \& Reese (1996, 2013) developed the hierarchy of influences model, which can be used as "levels of analysis" in studies of news gatekeeping processes (Shoemaker \& Vos, 2009, p. 31). Deciding what is news and what is not, and how it should be gathered and presented in an organization, depends upon several workers at different levels of a hierarchy (Fishman, 1980; Gans, 1979; Tuchman, 1978; Patterson \& Domingo, 2008). In particular, "levels of analysis are created by divid- ing up a continuum ranging from looking at the micro world of single people ... to looking at the macro world of countries and continents, and of course everything in between" (Shoemaker \& Vos, 2009, p. 31) The model includes the following categories, which appear in the findings: "individual," "routines," "organizational," "social institution," and "social system" (Shoemaker \& Reese, 1996, 2013; Shoemaker \& Vos, 2009). At each level, counts of statements are referenced in the Findings to demonstrate, within the limits of a case study based on 21 interviews, how much research participants had to say about these topics at each level. Each participant was invited to comment on each level of analysis. There was much more to be said about the organizational and institutional levels, and this is discussed further in the Findings.

Contemporary journalism studies and organizational change

It is helpful to position this article in relation to a few key studies that address how news organizations work with social media. Hermida (2010) looks at how Twitter users may treat the platform as a de facto news organization built to deliver ambient journalism. Hermida (2011) also examines how news organizations use Twitter and Facebook. These studies go into great detail about how organizations and users build practices and institutions around other people's 
platforms. One of this study's main contributions is that it examines a proprietary CMS built for news organizations by a news organization. One broad research question guided this study:

What evidence exists of a mutual shaping of technology process at each of five hierarchical levels in a news organization developing a platform for social journalism, and how did this process function?

METHOD

This case study is based on original data gathered in early 2011. "Case study" signifies "an empirical inquiry that investigates a contemporary phenomenon within its real-life context; when the boundaries between phenomenon and context are not clearly evident” (Yin, 1989, p. 23, quoted in Platt, 1992, p. 45). In this study, technological change is both context and variable. The case study method often develops more research questions than it answers (Yin, 2008) This is appropriate for studying an organization and its CMS under development as it necessitated renegotiation of norms and routines. Flyvbjerg (2006) identifies four types of case study: extreme cases (unusual, often single cases), maximum variation cases (a few cases that vary widely on one variable), critical cases (ones that logically represent many others) and paradigmatic cases (ones used to establish a metaphor or "broad theoretical domain"; p. 230). The case studied here is an extreme case. It is unusual but not

The Journal of Media Innovations 4.2 (2018),55-70 paradigmatic, and it is not a critical case since the ultimate development of a participatory journalism CMS does not rest on its success or failure. This case offered a fresh approach to cutting edge problems that have yet to be solved (p. 230).

Case selection and data collection

This study is based on 21 in-depth interviews conducted over the course of several weeks in January, February, and March of 2011 at a Midwestern news organization in existence for more than 100 years Interviews were conducted in one-on-one settings, either on the premises or at coffee shops and restaurants near the newspaper's main offices. Participants were provided with coffee or another beverage of their choice, if they wished, as a small token of thanks for their time and expertise. Questions related to the mutual shaping of technology, structured according to the hierarchy of influences model, were asked of every participant, and follow-up questions delved into their particular experiences.

Interview method

This case study employed an in-depth, semi-structured interview method of data collection. Weiss (1995) notes that this method "is good for developing detailed descriptions ... helps at integrating multiple perspectives ... and enables the researcher to describe processes" (pp. 9-11). These attributes ap- ply directly to this study, designed to provide detailed descriptions of complex news-making processes from multiple points of view, allowing for interpretation and synthesis of viewpoints as well as the identification of areas of interest and key variables for future research. Interview participants were contacted via email within two months of the original interviews to clarify statements, particularly those referenced here.

Members only

This study is told through the lens of the managers and employees in the news organization and does not include interviews with members of the public advisory committee because only members of the news organization could speak to both sides of the DI versus SST dynamic. The social shaping aspect of this study presumes an in-depth knowledge about the workings of the institution and the nature of the routines and professional norms at work before the new CMS was developed. Members of the public did not have that information, although their contributions were noted by several employees who worked with the advisory committee, an ad hoc group of health care and health insurance providers in the area.

\section{DATA ANALYSIS}

Transcribing the interviews produced about 500 pages of double-spaced text. Analysis of each transcript was conducted using a free qualitative data analysis 
software package for the Macintosh OS called the Text Analysis Markup System (TAMS) Analyzer. TAMS enables researchers to highlight portions of text and assign coded, hierarchical tags with the capability for adding subcategories. Codes can be searched and compiled across cases for further analysis. Out of a ream of interview data, only statements that made clear indications relating to the DI or SST perspectives were coded and counted. More than 500 codes were generated. As more nuanced codes were developed, it became necessary to return to previously coded interviews and apply the more detailed codes. Interviews were analyzed and coded for DI and SST themes a minimum of three times each.

Construct validity

Yin (2008) argues that case studies should connect data to theory through the development of a descriptive framework, which may be case-specific. Around this framework, evidence from the case is added to make meaningful, well-documented statements about the theory. For this study, a matrix of analysis was created. The MST construct was split into Diffusion of Innovations (DI) related observations and Social Shaping of Technology (SST) observations. They were balanced against one another at the five levels of the hierarchy of influences model from Shoemaker and Reese $(1996,2013)$ and Shoemaker and Vos (2009). The most challenging aspect of this research

The Journal of Media Innovations 4.2 (2018),55-70 was in describing changing perceptions. MST enables researchers to look at how an innovation evolves and at how perception about the innovation evolves. The social shaping of the perception of an innovation is a large factor in its overall social shaping and is included in this analysis.

\section{Operationalizing MST}

Identifying cause and effect in social shaping situations is difficult. It is common for "chicken-and-egg" problems to arise. This was dealt with through careful reconsideration of the data, always seeking to answer whether the technology was being brought to bear on norms, routines, and practices or vice versa. When it was unclear in an interviewee's statement which side of the dynamic it represented or when single statements were broad and seemed to discuss both influence of and influence on the CMS, the statement was left out of the count used to determine the prevalence of either DI or SST. To be counted, a statement from an interview subject had to apply clearly to one level of influence (individual, routines, organizational, etc.) and had to fall clearly on one side of the DI vs. SST dynamic.

\section{Participant Identification}

Participants were candid about their hopes and fears regarding the social journalism CMS and its future in their organization. Some of their feelings, if made public, might affect their standing in the organization. To protect identities, participants were labeled in terms of their department and then randomly given a number. Categories include News (1-11) Management (1-4), Design (1-2), and Marketing (1-4). Participants in the "Marketing" category sold ads and worked to market the organization; thus, Advertising was not considered a separate category. "News" and "Management" are separated because it helps to know which opinions were stated from positions of authority. "Management" refers to participants who had authority to give assignments and to alter work routines across multiple departments in the newsroom. The "Design" category refers to web designers employed by the organization. A brief description of the role of each participant is included in the Appendix.

\section{FINDINGS}

The findings are broken down according to the levels of the hierarchy of influences model. Basic counts of statements pertaining to DI or SST are presented. These are not statistically generalizable but are meant to show how participants conceived of or framed the innovation at each level. Generally, participants had much to say about the influence of the new CMS on the organization and on its relationships with other institutional actors. Participants had almost nothing to say about the possible impact this CMS might have 
on their work at the social systems level. I asked if it might influence their views on American journalism or journalism in capitalist culture, and generally the response is best summarized as: "Journalism is journalism."

Participants had relatively little to say about how the new CMS was affecting their individual news judgment or their routines even though the expectation was that this could become the primary method of news gathering, collaboration, and dissemination in the organization. In many cases, they were taking a "wait and see" approach. I interpret this to mean that participants saw the social journalism CMS as an experiment apart from what they "normally" do. This is evident in their discussion of the MST dynamic at the organizational level where it was not the fact that they socially shaped the technology that was interesting but how they characterized the CMS that bears noting. They were often skeptical of the innovation, which they saw as a risky experiment.

This shows institutional inertia, but it is important to note that this "newspaper" made much of its money from a cable television business until just before the data-gathering period for this study when family owners sold the cable business. Through the cable television arm, the company had been an internet service provider up to that point, and it had created television programs, various online media products and services, and an "online newspaper" CMS and advertising display service that it marketed to small and midsized news organizations around the country.

What is interesting is not that newspaper journalists balked at a social journalism CMS. What is interesting is that they generally gave it a lukewarm reception despite having experience in multimedia journalism, multi-platform content distribution, civic and citizen journalism, and CMS development for in-house use and broader sales and distribution. Development of the social journalism CMS was a logical continuation of years of innovation, but it seems to have been a bridge too far. Constructing and analyzing the MST dynamic according to the hierarchy of influences structure helps shed light on why that was the case.

Individual leve

The individual level of analysis was operationalized to refer to the personal characteristics, cognitive processes, and role conceptions of news workers, per Shoemaker \& Vos (2009, p. 47). When interviews were conducted, only one reporter regularly worked with the social journalism platform. She had worked on the site for one year as a reporter and community manager. Most observations at the individual level of analysis come from her; however, several journalists in the organization were assigned "beat blogs" in anticipation of moving them to the new CMS. Yet another reporter was being trained to start an environ- mental journalism site using the new CMS. It would have been a site unto itself built on the same social journalism scaffolding, but it never materialized.

Relating to the individual level, participants made 29 comments referring to DI and 11 related to SST. Most of the discussion centered on the reporter/community manager's (identified here as News1) cognitive processes and role conceptions as she related them or as her closest coworkers observed. The prototype site reporter saw the social journalism CMS as an innovation that disrupted her usual practice. She was a beat reporter at heart, but now she worked as a community manager. She dove in when it came to practicing social journalism, but when pressed on the issue of whether her concept of news was changing, the reporter said, "News is news. It never changes" (News1). Other reporters with beat blogs added that they still maintained a professional detachment from their communities. The prototype site focused solely on local health news and stakeholders. The health site reporter/community manager said news in the context of social journalism is "what's important to the health community or what they need to know about, just like any other news, I think - an important event or a person fighting a disease or a food bank. Those are all things I would have covered before" (News1). Her point was that all journalists serve communities and try to anticipate their informational needs, and she did not intend to change this approach although 
the social journalism CMS was built to require audience collaboration.

The reporter's comments about her unchanging heuristics belied the fact that her story choices changed. A content manager for the (traditional) online newspaper said, "There are stories that are [health site] stories that normally wouldn't have been covered - fundraisers, fun runs, $5 \mathrm{Ks}$, blood drives, hospital tours, even events like information meetings on how to become a Big Brother or Big Sister [mentor]" (News8). Stories that would have been briefs in the paper became multimedia packages designed to serve the health community: "In the paper, I wrote two inches. With the [site], I know this is of very big interest to [one of the larger groups] and to health in general, and so I pretty much rewrote the whole press release and have a whole schedule of activities, and I added photos and links" (News1). The nature of the social journalism CMS changed what was considered newsworthy. This is evidence of diffusion, and the reporter/community manager's resistance to admit that her news judgment was changing is counted as social shaping. She pushed back based on her education, training, and norms, even though it was not productive towards iterative CMS development.

The health site community manager was encouraged to pursue a story-as-conversation model of reporting (Management2). She had to employ her news judgment and answer what the community wanted to know based on their comments and emails. This is evidence of the diffusion of the CMS influencing individual news judgment. In an effort to shape the CMS, the reporter/community manager asked the designers for a "goals application" numerous times (News1). The plan was that the community manager and stakeholders would set goals for action on key issues and track progress. This was never completed, but it would have guided content, and the reporter was strongly in favor of adding it to future iterations. Her efforts at social shaping were noted, but resources for the project and management interest waned.

\section{Routines level}

The routines level of analysis was operationalized to mean references to repeated practices in news production and to news workers' "orientation to the audience" per Shoemaker \& Vos, 2009 (p. 53). Orientation to the audience is differentiated from role perception because it is about relationships rather than an internal definition of professional purpose. Orientation is role perception enacted.

There were 59 comments relating to DI and 9 relating to SST at this level. Concerns about disruptions to the health site community manager's routine were more widespread in the organization than concerns about changing news heuristics. A sort of shudder spread through the organization when journalists saw how much work was expected of the health site community manager. Most of the comments reflect how busy her daily routine became: "They've all told me, 'I don't know how you do it,' and they're kind of concerned about how they'll handle it, so it'll be interesting to see how it plays out" (News1). When planning the "experiment," the organization had intended to hire a second reporter for the health site. As one informant noted, "It's a tremendous amount of work to juggle the community, to keep the postings fresh, and I think there's been a lot of discussion: Should we add another reporter, add a clerk?" (Management3). In 31 separate statements, more than half of the DI-related comments here, respondents in News, Management, and Marketing identified the site manager's routine as cumbersome. I did not classify these comments as shaping the perception of the technology because they were direct observations of changes in routine.

When perceptions were expressed, I counted those statements as evidence of SST. Examples include when the reporter/community manager controlled her use of the technology at times to make her schedule more flexible, but that did not prevent her from feeling as though she were always on the job. Two other reporters said they were glad to alter their routines to contribute to the site, but their contributions were rare. The reporter/community manager worked day and night, covered myriad stories, wrote blurbs, and developed basic graphics for the web, and she appeared at public events asking new users to 
join the site and sometimes demonstrating the CMS for individual users. These were stressful changes in routine.

Organizational level

At the organizational level, more of a balance was observed. There were 106 statements relating to DI and 71 relating to SST. The operationalized definition of this level included comments about organizational strategy, boundaries, and "role shock," which refers to how workers may react when their role in an organization shifts (Shoemaker \& Vos, 2009, pp. 63-73).

The general idea that diffused throughout the organization was that the social journalism CMS was the "platform of the future." I considered this evidence of diffusion because participants were repeating language coming from the organization's management associated with the diffusion of the CMS rather than discussing how they were shaping their perception of it. Several journalists framed the CMS as another in a line of changes to content delivery. As one said, "We're already oriented. We're already digital first" (Management1). Others saw the social journalism CMS as the coming of a new form of journalism. Terms "conversation" and "community" came up often, suggesting that barriers between the public and the newsroom were coming down or at least that those buzzwords were diffusing particularly well.
Statements of the acceptance of change were counted as evidence of DI.

Additionally, the organizational chart was rearranged. Management made crucial decisions in terms of layoffs, new hires, and technology expenditures in 2010 and 2011 that related to the development of the social journalism CMS. The director of media strategies (Management2) was hired. Internally, several roles changed: "I switched jobs really because of the [health site] because we needed to take that model and that approach and replicate it in other areas" (Management4). The new organizational model involved merging marketing, journalism, and advertising to a greater degree than had been done before:

She [Management2] was talking about niche sites and her vision of the future - about how you'd have a marketing person in it, a journalist, and a sales person that were working pretty closely together for each site, and were kind of like the functional team for making that site go. It was so funny. I kind of put that in the back of my mind, but a year later I'm in a room with the sales person and the journalist and myself and we're visiting with a client. (Marketing3)

Several journalists also changed their role perceptions. The higher education reporter, who managed a beat blog, said, "I'm not talking at people anymore.
We're talking with people, and if [the health site] has done anything, it's done that for me" (News6). The introduction of the site diminished the separation of news/editorial and marketing/advertising in the organization. Job titles were changed, and several concepts borne out of the participatory nature of the site diffused, at least rhetorically, throughout. The plan was to create a social journalism platform and to test it with a networked health news site and to eventually, perhaps, use this model as the core means of delivering information for the entire operation. Journalists and those selling advertising for the organization understood this as a plan pending the health news site experiment. Thus, the concept of the social journalism CMS and its implications were diffused in the organization in clearly recognizable ways.

The same cannot be said of social shaping at the organizational level. Perceptions about the new CMS were being stated and re-framed in ways that indicated social shaping was happening, but the response was mixed and the discussion muddied as several interview subjects had not made up their minds about the project. This was true particularly among journalists in the organization. There were dozens of statements made about how attitudes around the newsroom shaped news workers' perceptions of the CMS and prototype site. These can be separated into two groups, the positive and negative "spin" on organiza- 
tional change. Positive spin framed this as another innovative experiment from a news organization with a history of innovation. In that sense, journalists tended to frame the social journalism CMS as the "new hope." Other comments relayed a general concern about the newspaper industry and about layoffs expected in the organization. These concerns hung like a cloud over this effort to innovate. Past layoffs and the threat of future layoffs always presented a threat. When the frame of reference was one of fear, the introduction of the new CMS was referred to as "the risky experiment." There were instances where during the same interview a participant would express both kinds of spin (Management1, Management3, News7, News11). Thus, there was social shaping going on, but many in the organization did not know what to make of the technology. Journalists, news management in particular, did not seem equipped to manage technological uncertainty when the technology in question had the potential to disrupt newsgathering and dissemination routines as well as their relationship to the audience.

Those who viewed the social journalism CMS as risky were also concerned that the site did not immediately make money. One participant said, "I think we're still in the somewhat development stage, an unsure stage about, 'Was this a good business decision?' I mean we think so, but we're not there yet" (Management3). Another added, "The biggest question is if it makes money, and I don't know honestly how many people we will get. Those are things I'm not really sure about. I know that's a calloused answer, but I think those are really it: 'How many people are reading it?' And, 'how much money is it making?' I don't have an answer to either one of those" (News9). Efforts to define the innovation constituted a battle of perceptions within the organization. Thus, at the organizational level of analysis, I have demonstrated how a development process can break down even when the diffusion of an innovation is underway; perhaps an iterative development dynamic cannot operate when social shapers are evenly split.

\section{Social institutional level}

The institutional level of analysis focuses on relationships with "forces outside of media organizations" (Shoemaker \& Vos, 2009, p. 32). This section refers to how the innovation influenced the organization and was influenced by it in its dealings with other groups from other large, organized social structures including the health care industry, advertisers from a variety of industries, the non-profit sector and higher education. At the institutional level of analysis, evidence of SST processes outweighs evidence relating to DI. This is the only level of analysis for which this is the case. There were 69 statements relating to SST and 66 relating to DI. Discussions of "usership" dominated the DI-related portion of the responses. State- ments in this vein refer to attempts to recruit individual users and groups from various institutions, such as the health care field, local government, and cancer survivors' groups. The push to invite users to join the site was considered evidence of diffusion because it fell on almost everyone in the news organization to try to bring in users and acquaint them with the CMS via the health site. Journalists throughout the organization made efforts, some substantial, some feeble, to try to bring users and advertisers to the site. It is not surprising that some efforts were half-hearted, since, as is stated in the previous section, many in the organization viewed this effort as an experiment.

Interview participants also noted how the advisory board, made up of health industry stakeholders, shaped the CMS. Members of the advisory board were concerned with the vitriol present in the comments sections in the online newspaper (Management2). The social media manager noted that a group of retired white men would meet almost daily at the coffee shop down the street from the newspaper's offices to anonymously troll the online newspaper's audience (Marketing2). To combat the trolls, real names were required on the health site and posts were associated with groups. At first, advisory board members demanded that comments be locked down so users had to join a group to comment on posts associated with that group. Site designers did as they were asked but had misgivings: "I think the thing about the internet 
is a lot of these communities sort of have to grow on their own and rather than trying to have these rules, I think it's better to provide incentives for good behavior and things like that rather than requiring identification. Then, I'm at odds with the general consensus of the community there" (Design2). There were a handful of large (several dozen member) groups that formed in the early stages of the site's rollout, and there were hundreds of groups in all. An active user needed to request to join half a dozen groups to put together a news feed and regularly comment.

The group structure was meant to help the community organize its information (Management2), but once members took ownership of groups, they wanted to protect their discursive turf. They had logical reasons for doing so, but the diffusion of the group structure and the social shaping of the comments structure resulted in a site that was uninviting, difficult to navigate, and bureaucratic: "After three months, we called everybody back in and said, 'What do you want to change?' And they said, 'It's too hard to use. We need to make it easier.” (Management2). Restrictions on commenting and the required use of real names were loosened. Designers ditched the original green background in favor of black text on a white background with a grid of photos. These were iterative changes to the code of the CMS influenced by health community stakeholders invited to serve on the advisory board.

The Journal of Media Innovations 4.2 (2018),55-70
By the time access issues were addressed, many users had likely given up on the site or had scaled back their usage. This limited traffic. Additionally, the networked health news site was (and is) kept in a "silo" apart from the "online newspaper." To the dismay of the original project designer (Management2), there was no systematic linking to the networked health news site news from the main site between the beta launch in April 2010 and the re-launch in March 2011. Links from the main news site to the health news site were few and far between during this period. After March 2011, more regular linking was encouraged, but the damage to traffic for the health site was already done, according to the site's designer (Management2). Thus, there was iterative development including social shaping at the institutional level, but the site's popularity may have been hindered by hesitant efforts at diffusion as well design flaws arising from open input in early social shaping.

\section{Social system leve}

The social system level of analysis was operationalized to refer to perceptions only. It asked how journalists in the organization saw the American political economy and its media system influencing their coverage and how working with the new CMS might change those perceptions. At this level of analysis, only 17 relevant comments were observed, 9 relating to DI and 8 to SST. The CMS encouraged a few participants to acknowledge a potential future for social journalism. One informant noted, "It's creating a safe place, a trusted place for people to have conversations about important issues, and I think that's the influence" (Management4). Others couched their perception of the CMS and related changes in the organization according to existing social ideals, i.e. the role of journalism in service to democracy, but participants had little else to say about a level of analysis far removed from their day-to-day work life.

\section{DISCUSSION}

Boczkowski (2004a) wrote, "Additional research is needed to further the development of the mutual shaping lens in the analysis of new media ... future work could expand the process of theory building by linking general dynamics of technological and social change with an exploration of potentially specific features of various kinds of artifacts" (p. 263). MST can help to examine closely what happens when innovative media technologies fail. The goal is not to assign blame but to look at processes and social conditions that may have contributed to the unsuccessful introduction of a social journalism CMS. Let us connect theory at each level of analysis:

Individual level and MST

Analysis at this level suggests that the MST dynamic is not easy to apply when the same people have a say 
in the shaping and adoption of an innovation. Boczkowski (1999) described a mutual shaping process in an online community where the technology influenced users at a deeply personal level, and users influenced the technology such that it did more than its developers thought it could: "A mutual shaping perspective is best suited to capture the complexity, unpredictability, and recursivity of what goes on in a communication environment" (p. 104). MST enables us to look for uses developers had not intended down to the individual user level.

In this case, the reporter at once wanted to limit the ability of the innovation to shape her heuristics and she wanted shift the function of the site to serve her community by setting and tracking community health goals, which might have been revolutionary for a news site. Thus, there was an attempt at dynamic shaping, but the organization stopped developing the CMS in earnest when it did not prove to be particularly popular, roughly one year after these interviews took place or about two years after the site was launched. At the individual level, there was evidence of mutual shaping, but it ultimately did not help the project to fly.

Routines level and MST

Study participants did not describe these changes in routine as something that could be managed by applying or modifying existing norms. The way the site was rolled out, most of the pressure to perform was placed on one journalist. This helps explain why there was much less discussion of social shaping than there was concern about the impact of its diffusion at this level.

Organizational level and MST

There was little interest in trying to shape the CMS proactively at the organizational level, but it must be understood that this was during a time of industrywide layoffs and steep drops in advertising revenues that contributed to the sell-off of the cable business in this organization. Design team members focused most of their work each day on this project, but they had to maintain the traditional online newspaper and other properties as well. The primary product team (Management2 and News1) was often isolated from the rest of the newsroom. It is not surprising that those outside of this sphere of influence took a "wait-and-see" approach. Few were absolutely for or against the social journalism CMS, which suggests reasonable reticence on the part of people with journalism jobs to do, but if this were compared to the atmosphere in media startups, that kind of caution might be seen as a detriment. The thoughtful, careful approach to technological innovations that helped the organization to survive and helped the journalists to continue to get quality work done in a multimedia environment may have hindered this "experiment."
The organization's survival instincts may be what killed this "new hope."

Social institutional level and MST

Little was said that can shed light on how the mutual shaping dynamic functioned at the social system level. Thus, the social institutional level brings us to the end of the discussion. The MST construct lets us examine how efforts at creating and iterating a smallbut-functioning public sphere might fail not just because of "bad design" or failure to listen to users but because new solutions create their own problems and users have their own bad ideas that need to be iterated out. The conceptual designer of the social journalism site (Management2) argued it was not fully supported, that a good-faith effort at introducing the technology would have included featured links on the main online newspaper site and the development of a goals application to maximize user engagement. In hindsight, the news organization was built to incorporate community input for a health news site, but it was not geared for iteration the way a media startup might be if it were trying to create a new framework for news production and dissemination built on social media and blogging tools with paid underwriting and paid group sponsorships as key revenue sources.

There were limits to enthusiasm, limits to resource allocation, and limited trust on the part of many in the news organization. Some of the efforts to intro- 
duce the social journalism CMS were half-hearted. Social shaping was allowed, particularly at the level where the news institution related to other institutions such as health providers and local leaders, but this kind of iterative startup dynamic needs outside energy to keep churning. The result of this "risky experiment" was to create a failed attempt at a marriage between social media and news.

\section{CONCLUSION}

The primary question in this case study was whether this social journalism CMS was seen in the organization developing it as a tool for journalists to shape or as an innovation to be "dealt with" and either adopted or not. My analysis of 21 in-depth interviews with journalists, managers, marketers, and designers about this dynamic, messy process, finds that the social journalism CMS was viewed more as a disruption apart from the "real" work of running the news organization than as an opportunity to create the next great news platform. Tallying up the anecdotal but carefully analyzed comments, 269 statements framed this more as a process of diffusion, while 168 framed it as a social shaping effort or opportunity. Employees and community stakeholders were invited to help iteratively develop a social journalism CMS, but almost all of them had other jobs to do.

A final note: The topic, health news, may not have been ideal for introducing a participatory CMS, since many health issues are private, but by the time most participants in this study were aware of the new social journalism CMS, the topic had already been selected and staff and management were more focused on other questions related to its rollout. For this reason, the question of the topic itself does not appear at length in the analysis above.

The choice to build a health site as the prototype for the social journalism CMS was discussed at length with the original designer and project manager (Management2), and it was expressed that since users had control over what they published, they would still be able to use the site to glean useful information and to contribute to news discussions without needing to fear for their privacy. Additionally, it was thought that the personal nature of health news might be a benefit because people are invested and perhaps more likely to engage in health news in ways they might not be with other topics. The topic was not up for discussion in the organization, however. Had the site been a success the next planned site to be built on the CMS would have been an environmental news site, which again was thought to be a topic that encouraged deep engagement.

It is also worth reiterating the organizational historical context of this project. The organization had built and marketed a small-market CMS for news before, but the socially networked CMS for news was not simply another "online newspaper" CMS. It was a new way of doing news that included even more participation than the civic journalism efforts tried at the paper roughly 10-15 years previously. This, the social journalism CMS, was their latest news product, not their first technology startup, but it failed long before being implemented company-wide.

\section{Mark A. Poepsel}

Southern Illinois University at Edwardsville

mpoepse@siue.edu 


\section{REFERENCES}

Bardoel, J. (1996). Beyond journalism: A profession between information society and civil society. European Journal of Communication, 11(3), 283-302. http://ejc. sagepub.com/content/11/3/283.short

Bardoel, J., \& Deuze, M. (2001). 'Network journalism': Converging competencies of old and new media professionals. Australian Journalism Review, 23(3), 91-103. https://scholarworks.iu.edu/dspace/handle/2022/3201

Bijker, W., Hughes, T., \& Pinch, T. (1989). The social construction of technological systems: New directions in the sociology and history of technology. Cambridge, MA: MIT Press.

Boczkowski, P. J. (1999). Mutual shaping of users and technologies in a national virtual community. Journal of Communication, 49(2), 86-108. http://onlinelibrary.wiley.com/doi/10.1111/j.1460-2466.1999. tbo2795.x/abstract

Boczkowski, P. J. (2004a). The Mutual Shaping of Technology and Society in Videotex Newspapers: Beyond the Diffusion and Social Shaping Perspectives. Information Society, 20(4), 255-267.

Boczkowski, P. J. (2004b). The Processes of Adopting Multimedia and Interactivity in Three Online Newsrooms. Journal of Communication, 54(2), 197-213. http://onlinelibrary.wiley.com/ doi/10.1111/j.1460-2466.2004.tbo2624.x/abstract
Deuze, M. (2006). Participation, remediation, bricolage: Considering principal components of a digital culture. The Information Society, 22(2), 63-75. https://scholarworks.iu.edu/dspace/handle/2022/3200

Deuze, M. (2008). The changing context of news work: Liquid journalism and monitorial citizenship. International Journal of Communication, 2, 848-865. http:// ijoc.org/index.php/ijoc/article/view/290/197

Deuze, M. (2011). Managing Media Work. London: Sage Publications.

Fishman, M. (1980). Manufacturing the news. Austin, TX: University of Texas Press.

Flichy, P. (2007). Understanding technological innovation: A socio-technical approach. Northampton, MA: Edward Elgar Publishing.

Flyvbjerg, B. (2006). Five misunderstandings about case-study research. Qualitative Inquiry, 12(2), 219245. http://qix.sagepub.com/content/12/2/219. short? $\mathrm{rss}=1 \&$ ssource $=\mathrm{mfr}$

Gans, H. (1979). Deciding what's news. New York: Pantheon Books.

Hackett, R. A. (2006). Is peace journalism possible? Three frameworks for assessing structure and agency in news media. Conflict and Communication Online, 5(2), 1-13.

Hermida, A. (2010). From TV to Twitter: How ambient news became ambient journalism. Media/Culture Journal, 13(2). http://journal.media-culture.org.au/ index.php/mcjournal/article/viewArticle/220
Hermida, A. (2011). Mechanisms of participation. In Singer, J. B., Hermida, A., Domingo, D., Heinonen, A., Paulussen, S., Quandt, T., Reich, and Vujnovic, M. (Eds.), Participatory journalism: Guarding open gates at online newspapers (pp. 11-33). Hoboken, NJ: Wiley-Blackwell.

Hermida, A. (2012). Social journalism: Exploring how social media is shaping journalism. In E. Siapera \& A. Veglis (Eds.), The handbook of global online journalism (pp. 309-328). Hoboken, NJ: Wiley. http://www.wiley.com/WileyCDA/WileyTitle/productCd-1444338552.html

Hermida, A., \& Thurman, N. (2008). A clash of cultures: The integration of user-generated content within professional journalistic frameworks at British newspaper websites. Journalism practice, 2(3), 343-356. http://www.tandfonline.com/doi/ abs/10.1080/17512780802054538

Jalote, P., \& Agrawal, N. (2005, December). Using defect analysis feedback for improving quality and productivity in iterative software development. In Information and Communications Technology, 2005. Enabling Technologies for the New Knowledge Society: ITI 3rd International Conference on (pp. 703-713). Ieee. https://www.iiitd.edu.in/ jalote/papers/DefectPrevention.pdf 
Karlsson, M., \& Strömbäck, J. (2010). Freezing the flow of online news. Journalism Studies, 11(1), 2-19. http://www.tandfonline.com/doi/ abs/10.1080/14616700903119784

Küng, L. (2008). Strategic management in the media: Theory to practice. Thousand Oaks, CA: Sage.

Lewis, S. C. (2012). From journalism to information: The transformation of the Knight Foundation and news innovation. Mass Communication and Society, 15(3), 309-334. http://sethlewis.org/wp-content/ uploads/2014/10/2012-Lewis-2012-MCS.pdf

Lievrouw, L. A., \& Livingstone, S. M. (2002). Handbook of new media: Social shaping and consequences of ICTs. Thousand Oaks, CA: Sage.

MacKenzie, D., \& Wajcman, J. (1999). The social shaping of technology. Maidenhead, UK: Open University Press.

Nip, J. Y. M. (2009). Routinization of Charisma. In J. Rosenberry \& B. S. J. III (Eds.), Public Journalism 2.o: The Promise and Reality of a Citizen-Engaged Press (pp. 135-148). London: Routledge.

Paterson, C., \& Domingo, D. (2008). Making online news: The ethnography of new media production. New York: Peter Lang.

Platt, J. (1992). "Case study" in American methodological thought. Current Sociology, 4o(1), 17-48. http://csi. sagepub.com/content/40/1/17.full.pdf+html
Poepsel, M. A. The mutual shaping of technology in a news establishment: Social journalism and organizational change. (Unpublished doctoral dissertation) University of Missouri-Columbia.

Reese, S. D. (2001). Understanding the global journalist: A hierarchy-of-influences approach. Journalism Studies, 2(2), 173-187.

Rogers, E. M. (2003). Diffusion of Innovations (5th ed.). New York: Free Press.

Rodgers, S. (2015). Foreign objects? Web content management systems, journalistic cultures and the ontology of software. Journalism, 16(1), 10-26. http://www. academia.edu/7818339/Foreign_objects_Web_content_management_systems_journalistic_cultures_ and_the_ontology_of_software

Shoemaker, P. J., \& Reese, S. D. (1996). Mediating the message: theories of influences on mass media content (2nd ed.). White Plains, NY: Longman.

Shoemaker, P.J., \& Reese, S.D. (2013). Mediating the message in the 21st Century: A media sociology perspective. New York: Routledge.

Shoemaker, P. J., \& Vos, T. P. (2009). Gatekeeping Theo$r y$. New York: Routledge.

Singer, J. B. (2011). Journalism in a network. In M. Deuze (Ed.), Managing Media Work (pp.103-109). Thousand Oaks, Ca.: Sage.
Singer, J. B., Hermida, A., Domingo, D., Heinonen, A. Paulussen, S., Quandt, T., Reich, and Vujnovic, M. (2011). Participatory journalism. Hoboken, NJ: WileyBlackwell.

Tuchman, G. (1978). Making news: A study in the construction of reality. New York: Free Press.

Voakes, P. S. (1997). Social influences on journalists' decision making in ethical situations. Journal of Mass Media Ethics, 12(1), 18-35.

Weiss, R. (1995). Learning from strangers. New York: Free Press.

Yin, R. (1989). Case study research: Design and methods (2nd ed.). Thousand Oaks, CA: Sage.

Yin, R. (2008). Case study research: Design and methods (4th ed.). Thousand Oaks, CA: Sage. 
APPENDIX: TABLE OF PARTICIPANTS

Labe Description

Marketing1 Director of Sales and Marketing, responsible for digital product development.

Marketing2 Manager of social media for the business side of the organization

Marketing3 Manager of marketing for the newspaper

Marketing4 Leader of digital sales representatives

Design1 Manager responsible for development of the CMS and prototype website, also managed several other online properties

Design2 Designer responsible for user interaction features on the prototype website and on other company websites

News1 Beat reporter, news manager of the prototype site

News2 Education beat reporter also responsible for a blog

News3 Features reporter

News4 Manager of an affiliated community news site

News5

News6

News7

News8

News9

General assignment reporter and part-time graduate student

Higher education beat reporter also responsible for a blog

Arts beat reporter, responsible for entertainment website

Director of the flow of content for the "online newspaper"

Sustainability beat reporter, trained to manage a second social journalism site that was not sustained

News10

Online editor for the sports niche site

News11 Copy desk chief

Management1 Managing Editor, newspaper

Management2 Director of Media Strategies, conceptual designer of the CMS

Management3 Community Editor, story supervisor across platforms

Management4 Assistant Director of Media Strategies, developed new markets for news products 